\title{
Handicapped Children in Preschool Playgroups
}

\author{
ELIZABETH GRANTHAM
}

British Medical fournal, 1971, 4, 346-347

The playgroup movement started 10 years ago as a "do-ityourself" nursery school in London. It has now mushroomed into a national organization named the Preschool Playgroup Association (P.P.A.) with a membership of over 7,000 groups. Each branch area has an organizer whose expenses are paid by the local groups, and centrally there are two national advisers who are paid from a Government grant. The Peterborough and district branch, to which I am medical adviser, has 23 playgroups catering for nearly 700 children. The groups are run by the mothers through a committee which appoints a paid superviser and, if necessary, paid assistants. The mothers themselves help on a rota system.

P.P.A. playgroups are non-profit making, independent, and of ten registered as a charity. The numbers of children vary from 6-12 in home groups to $15-30$ in groups held in rented premises. The usual charge is $15-25 \mathrm{p}$ a session, and two to five sessions of two to three hours a week are usually offered for each child. The groups have to be registered under the child-minder regulations and now come under the social services committee of the local authorities.

\section{Benefits to Children and Mothers}

The P.P.A. believes that admitting handicapped childrenin the broadest sense of the term-to normal groups helps not only the handicapped but also their mothers and the rest of the community. The handicapped child gains from using, in a familiar, secure environment, slides, climbing frames, trucks and trikes; from playing with expensive constructional or educational toys; and from making a mess with sand, water, dough, clay, or poster or finger paints. I have seen an athetoid child just able to walk with support swing all over a climbing frame, and a spina bifida child throw down her crutches, struggle up the steps of a slide, go whizzing down, and shuffle on her bottom back to the steps again. These children watched the non-handicapped children for a long time before they attempted to copy, but when they found that they could do it too their whole horizon widened.

A handicapped child tends at first just to sit and watch other children-this alone is often a novel experience. He then begins to copy other children's activities, and gradually he joins in with group activities-singing, games, action stories, etc.-and later in creative imaginative play with a small group. By these means he begins to develop a relationship with the other children. This interaction between the children has great therapeutic value.

Most handicapped children are more than usually dependent on their mother. The P.P.A. policy is to encourage a mother to stay with her child until he or she has settled in. After a few mornings watching other mothers go the child will usually request that his goes too. Even when a mother has to stay every morning for months I have seen confidence increasing in an emotionally disturbed child which has made it well worth while. The handicapped child has to become confident that the playgroup can take the place of mother, and in this Denartment of Paediatrics, Peterborough District Hospital, Peterborough
PE3 6DA

ELIZABETH GRANTHAM, M.B., B.S., Medical Adviser to Peter borough and District Branch of the Preschool Playgroup Association way a playgroup can be a useful stepping stone to a fulltime or residential school.

A mother of a handicapped child who joins a playgroup feels less isolated. She becomes part of a community activity and makes social contacts. She also gets sympathy, understanding, and practical help. Once her child has settled in a mother can get some time off to get her hair done, to shop, etc. I have noticed an improvement in the general grooming of these mothers.

\section{Mentally Handicapped Children}

A mother may have difficulty in separating herself from a dependent child even if she knows it will be beneficial for both of them, and the playgroup can ease this separation. A mother of a mentally retarded child may come to accept the reality of his condition more easily when she sees him with other children. She can see that his pictures are still a haphazard mess when the others have reached the stage of symbolic representation, and that he still finds a simple jigsaw difficult while the others quickly do more complicated ones.

Several parents of mongol children have been sure their child could manage ordinary school but after a time in the playgroup have admitted that a special school might be more suitable. This means that the special school will get wholehearted support from the parents rather than a feeling of resentment that their child has been "sent" there.

The playgroup community benefits from having handicapped children. The staff and the other mothers quickly acquire a new insight into the problems of handicaps, and this removes the "fear" that is often felt when seeing the abnormal. Children of this preschool age group tolerate and accept handicaps and differences quite easily and often show great understanding and care. For example, a mongol child was a great favourite in one group, and whenever the children saw another mongol they would rush up and say they had seen Anthony's brother or sister.

\section{Composition of Group}

If there are more than $10 \%$ of problem cases in a playgroup its balance and atmosphere are upset. This does not mean that the group can take only $10 \%$ of handicap cases. Many non-handicapped children are problem cases and many handicapped children are no problem at all.

Many areas are providing groups only for handicapped children, but I believe it is much better at preschool age to mix the handicapped and non-handicapped. Handicapped children have to grow up and live in a normal community, and the sooner they become integrated into that community the easier it is for them and their families. The aim should be to get them to think of themselves as part of the community doing what all the other children do, not to regard themselves as something special and odd.

Since children imitate those around them a minority of handicapped children in a group will tend to pick up the behaviour, activities, and mannerisms of the majority, and this aids their general development and progress.

It is of the greatest help to any handicapped child to be provided with a one-to-one relationship with an understanding and caring adult. I think this situation can be met in a 
playgroup. So far the groups themselves have found the necessary extra help either on a voluntary basis or paid for from their own limited funds. If more use is to be made of offers from groups to help with handicapped children they should receive financial help for either a welfare assistant or an extra helper, according to the need of the child. The groups, which are run by ordinary parents, also need the help and advice of experts in dealing with any problem that may arise.

Before "placing" a child a doctor needs information about local groups. He could obtain this from the local playgroup advisor, who could also provide a feed back of information in the child's progress.

\section{Future Role}

Playgroups are eager to help handicapped children and they can offer them so much, but we must be careful not to overtax their good will and limited resources. The playgroup movement is a community effort and, while groups will need extra help for the extra load brought by handicapped children, they must not be "taken over" by any department. The views of the parents of the handicapped and other playgroup children must be asked for and respected, and they must be free to refuse a child.

Two or three sessions a week in a playgroup might be combined with other treatment in a handicapped child who is under the care of a special department. If a careful partnership can be worked out between the independent playgroups and the medical services in an area both parties could gain. The groups would get expert advice and backing for their aims, and the medical services would get not only help for the handicapped but might also extend the partnership to pick out children in need of attention before attending school -for example, late talkers, children with emotional difficulties, etc.

Some procedure for the placing of handicapped children in playgroups would have to be worked out. Most established groups offer a free place for a needy child and they choose the child for it. If they are to be asked by a doctor from the children's department to take a child they should have the financial and advisory help I have mentioned. The Diagram indicates a possible method of placing children.

The playgroup movement has arisen spontaneously to fill a

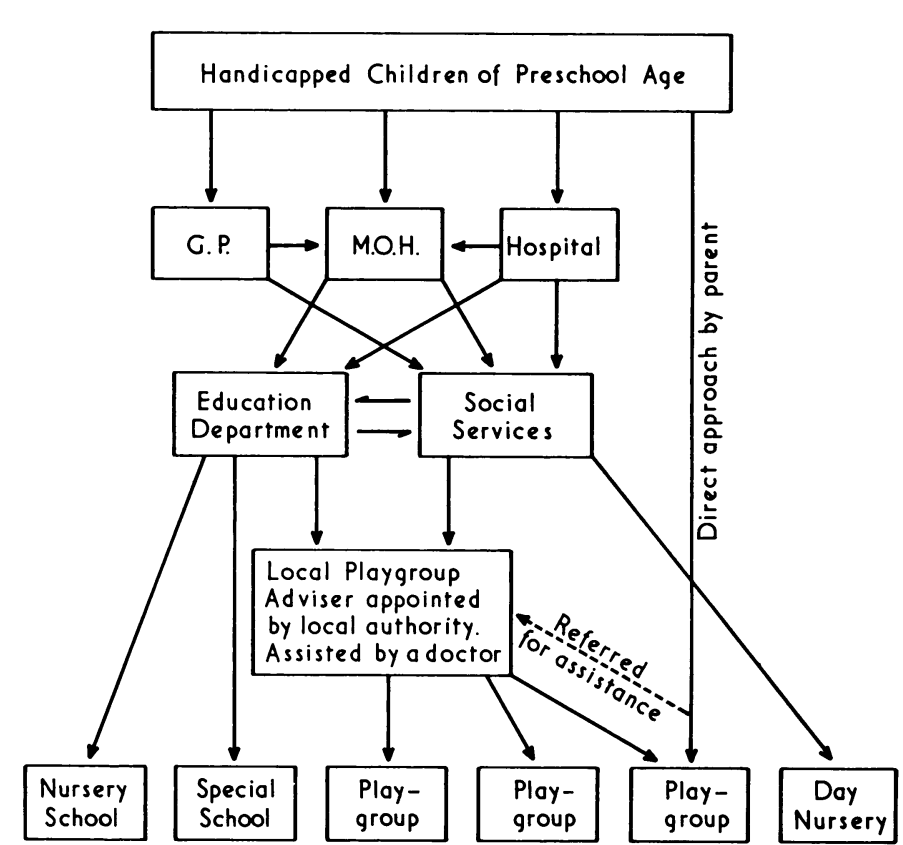

Proposed placing of preschool handicapped children.

need created by the modern small, isolated family. In a recent survey in Newcastle upon Tyne it was noted that onethird of families on new housing estates felt isolated.' This isolation is felt even more by the handicapped children and their mothers. I believe it is only right that they should also gain help and support from what in many ways is a new social equivalent of the old tribe or clan. The movement should continue as a community effort and work in partnership with the local health and welfare services, remembering that the keystone of this movement is parent participation.

\section{Reference}

1 Court, S. D. M., British Medical fournal, 1971, 2, 125.

\section{One Hundred Years Ago}

From the British Medical fournal, 4 November, 1871

\section{TATTOOED FROM HEAD TO FOOT}

There is now exhibiting in medical circles in Vienna a remarkable instance of tattooing of the whole body. According to his own account, the man, a Greek by birth, had been a pirate, and had also carried on brigandage on the continent. Seven years ago, he and five companions were taken prisoners by one of the wild tribes of Asia. Three of them were put to death; but this man, with two others, was preserved alive and literally tattooed over the entire body. The operation lasted two months, and was performed by six men, who each day operated on different parts of the body. The proceeding caused horrible pain; and his two companions died under the treatment. His body is covered from head to foot with delineations of men, animals, and fabulous things. The colouring material used for the figures appears to be indigo, the ground, especially on the chest and abdomen, being vermilion; here and there, about a line's breadth of the normal colour of the skin can be seen. The hands and the soles of the feet are coloured red, but have no figures. On the face and neck are inscriptions in characters resembling Arabic. The skin has the general appearance, to the sight and touch, of bluish-grey velvet. 